\title{
Cerebral Venous Thrombosis in Behçet's Disease Patients Compared to Other Causes of Cerebral Venous Thrombosis: a Retrospective Study
}

\author{
Mine Hayriye SORGUN, Sefer RZAYEV, Mustafa Aykut KURAL, Seyda ERDOĞAN, Canan YÜCESAN \\ Department of Neurology, Medical Faculty of Ankara University, Ankara, Turkey
}

\begin{abstract}
Objectives: This study aims to report the outcomes of patients with Behçet's disease (BD) with cerebral venous thrombosis (CVT) due to BD compared to patients with CVT due to other causes and to discuss the treatment options.

Patients and methods: Files of 47 patients admitted to our outpatient clinic for CVT between January 2007 and November 2014 were retrospectively reviewed. Patients were divided into two groups; group 1 included 21 CVT patients with BD ( 9 males, 12 females; mean age $47 \pm 12$ years; range 27 to 69 years) and group 2 included 26 CVT patients without BD (11 males, 15 females; mean age $45 \pm 16$ years; range 25 to 79 years). We collected data for diagnosis for BD and CVT, duration of all medications, functional system involvement, baseline Expanded Disability Status Scale scores, modified Rankin Scale scores at follow-up, and localizations of lesions in brain magnetic resonance imaging and magnetic resonance venography.

Results: Mean follow-up duration was four years in group 1 and two years in group 2. There was no significant difference between the groups regarding age, sex, neurological symptoms/findings and baseline Expanded Disability Status Scale scores. Localizations of occluded sinus in group 1 and group 2 were similar. For acute CVT, patients were treated with intravenous high dose prednisolone in group 1 and with anticoagulant in group 2 . Follow-up modified Rankin Scale score was 0 in both groups.

Conclusion: Our study revealed similar clinical and radiological findings in CVT patients with or without BD. Although medications used for treatment were different between the groups, treatment responses were good in both groups. Treatment with prednisolone may be sufficient and anticoagulation therapy may not be necessary for acute CVT attacks in BD.

Keywords: Behçet's disease; cerebral venous thrombosis; intracranial hypertension syndrome.
\end{abstract}

Behçet's disease $(\mathrm{BD})$ is a multisystem relapsing inflammatory disorder that is thought to be an inflammatory perivasculitis. It bears the name of the Turkish dermatologist, Hulusi Behçet, who first described it in 1937. ${ }^{1}$ Neurological involvement (neuro-Behçet's disease [NBD]) is a rare manifestation; however, it is one of the most serious causes of long-term morbidity. NBD predominates in males and commonly develops a few years after the onset of other systemic features of $\mathrm{BD}$, with a mean duration of three to six years. Only $6 \%$ of the cases may coincide or even precede $\mathrm{BD}^{2,3}$ International Diagnostic
Criteria for $\mathrm{BD}$ are applied to diagnose BD. ${ }^{4}$ The most important target in NBD is the central nervous system, and it can affect the parenchymal or extra-parenchymal tissues. The common symptoms include focal parenchymal lesions, vascular thrombosis, arterial vasculitis, and aseptic meningoencephalitis, particularly brainstem encephalitis. Other appearances are intracranial aneurisms, extracranial aneurisms/ dissections, tumor-like-NBD, and optic neuropathy. 3,5

Cerebral venous thrombosis (CVT) may be seen as a result of NBD. Actually, BD is one of 
the most common causes of CVT in the countries along the ancient Silk Road. ${ }^{6}$ CVT may be the first clinical manifestation and the venous involvement may affect veins of different size with tendency for thrombosis. ${ }^{7-9}$ In this study, we aimed to report the outcomes of patients with BD with CVT due to $\mathrm{BD}$ compared to patients with CVT due to other causes and to discuss the treatment options.

\section{PATIENTS AND METHODS}

Files of 47 patients who admitted to our Medical Faculty of Ankara University, Neurology clinic for CVT between January 2007 and November 2014 were retrospectively reviewed. Diagnosis of $\mathrm{BD}$ was established according to the international study group for BD criteria. ${ }^{4}$ Patients were divided into two groups; group 1 included 21 CVT patients with $\mathrm{BD}$ (9 males, 12 females; mean age $47 \pm 12$ years; range 27 to 69 years) and group 2 included 26 CVT patients without BD (11 males, 15 females; mean age $45 \pm 16$ years; range 25 to 79 years). For each patient in both groups, we collected the data for diagnosis of $\mathrm{BD}$ and CVT, medications used, functional system involvement which was assessed by using the Kurtzke Functional Systems Scale for each system, and the Expanded Disability Status Scale (EDSS) scores. We evaluated the severity of disease with modified Rankin Scale (mRS) scores at follow-up. We defined severe disability as $>3$ of $\mathrm{mRS}$ scores. In addition, we recorded the results of brain magnetic resonance imaging and cerebral magnetic resonance venography. The study protocol was approved by the Ankara University School of Medicine Ethics Committee. A written informed consent was obtained from each patient. The study was conducted in accordance with the principles of the Declaration of Helsinki.

\section{Statistical analysis}

We performed statistical analysis using the SPSS for Windows version 16.0 software (SPSS Inc., Chicago, IL, USA). We expressed descriptive statistics as mean \pm standard deviation for normally-distributed continuous variables and median and interquartile range for non-normally distributed variables. We compared the group rates using a chi-square test and the means using Student's t test. We considered a $p$ value of $<0.05$ to be statistically significant.

\section{RESULTS}

Patients' characteristics are shown in Table 1. The mean durations of BD and NBD were $11.50 \pm 9$ years (range 0 to 31 years) and $3.86 \pm 4$ years (range 0 to 18 years), respectively. Systemic involvement signs of $\mathrm{BD}$ were oral aphthae $(n=21)$, genital ulcer $(n=20)$, uveitis $(n=12)$, arthritis $(n=16)$, skin involvement $(n=7)$, deep venous thrombosis (DVT) $(n=4)$, gastrointestinal system (GIS) involvement $(n=3)$, and epididymitis $(\mathrm{n}=1)$ (Table 1). The mean follow-up durations for groups 1 and 2 were four years (range 0 to 18 years) and two years (range 1 to 5 years), respectively.

Patients in group 1 had antiphospholipid syndrome $(n=1)$, postpartum period $(n=4)$, methylenetetrahydrofolate reductase gene mutation $(n=3)$, Factor $V$ Leiden mutation $(n=1)$, polycythemia vera $(\mathrm{n}=2)$, protein $\mathrm{C}$ deficiency $(n=1)$, systemic lupus erythematosus $(n=1)$, Sjögren's syndrome $(n=1)$, Crohn's disease $(n=1)$, infection $(\mathrm{n}=2)$, and idiopathic $(\mathrm{n}=9)$.

In group 1,16 patients had only intracranial hypertension signs (headache, $\mathrm{n}=16$; papilloedema, $\mathrm{n}=8$; sixth nerve palsy, $\mathrm{n}=2$; nausea/vomiting, $\mathrm{n}=4$ ). Five patients (23.8\%) had parenchymal involvement signs beside intracranial hypertension signs. CVT course was monophasic in all patients. While median EDSS score was 0 in patients who only had CVT, the score was between 0 and 1 in patients who also had parenchymal involvement (Table 1). In group 2, 24 patients had intracranial hypertension signs (headache, $\mathrm{n}=24$; papilloedema, $\mathrm{n}=10$; sixth nerve palsy, $\mathrm{n}=2$; nausea/vomiting, $\mathrm{n}=4$ ) and parenchymal involvement developed in six patients with median EDSS score of 0 (range 0 to 3 ). Involvement of functional systems including pyramidal, brain stem, sensory, bowel and bladder functions, visual, cerebellar and mental systems and baseline EDSS scores were similar in both groups (Table 1).

In group 1, localizations of CVT were superior sagittal sinus $(n=2)$, superior sagittal sinus and transverse sinus $(n=1)$, superior sagittal sinus and transverse sinus and sigmoid sinus $(n=1)$, only transverse sinus $(n=11)$, transverse sinus and sigmoid sinus $(n=2)$, transverse sinus and 
Table 1. Epidemiologic and clinical characteristics of cerebral venous thrombosis patients with or without Behçet's disease

\begin{tabular}{|c|c|c|c|c|c|c|c|c|c|c|c|}
\hline & \multicolumn{5}{|c|}{ CVT patients with BD $(n=21)$} & \multicolumn{5}{|c|}{ CVT patients without BD $(n=26)$} & \multirow[b]{2}{*}{$p$} \\
\hline & $\mathrm{n}$ & $\%$ & Mean \pm SD & Median & Min.-Max. & $\mathrm{n}$ & $\%$ & Mean \pm SD & Median & Min.-Max. & \\
\hline Age (years) & & & $47.0 \pm 11.68$ & & $27-69$ & & & $45 \pm 16$ & & $25-79$ & NS \\
\hline \multicolumn{12}{|l|}{ Sex } \\
\hline Female & 12 & 57.1 & & & & 15 & 57.7 & & & & NS \\
\hline Male & 9 & 42.9 & & & & 11 & 42.3 & & & & \\
\hline Behçet's disease duration & & & $11.50 \pm 9.42$ & & $0-31$ & & & & & & \\
\hline NBD duration & & & $3.86 \pm 4.21$ & & $0-18$ & & & & & & \\
\hline \multicolumn{12}{|l|}{$\mathrm{ICH}$} \\
\hline Headache & 16 & 76.19 & & & & 24 & 70.6 & & & & NS \\
\hline Papilloedema & 8 & 38.09 & & & & 10 & 38.5 & & & & NS \\
\hline Sixth nerve palsy & 2 & 9.52 & & & & 2 & 7.7 & & & & NS \\
\hline Nausea/vomiting & 4 & 19.05 & & & & 3 & 11.5 & & & & NS \\
\hline EDSS & & & & 0 & $0-1$ & & & & 0 & $0-3$ & \\
\hline Pyramidal (+) & 1 & 4.76 & & & & & & & & & \\
\hline Brain stem (+) & 0 & 0 & & & & & & & & & \\
\hline Sensory (+) & 2 & 9.52 & & & & & & & & & \\
\hline Bowel and bladder functions (+) & 0 & 0 & & & & & & & & & \\
\hline Visual (+) & 1 & 4.76 & & & & & & & & & \\
\hline Cerebellar (+) & 0 & 0 & & & & & & & & & \\
\hline Mental & 0 & 0 & & & & & & & & & \\
\hline \multicolumn{12}{|l|}{ Other symptom } \\
\hline Genital ulcer & 20 & 95.23 & & & & & & & & & \\
\hline Uveitis & 12 & 57.14 & & & & & & & & & \\
\hline Arthritis & 16 & 76.19 & & & & & & & & & \\
\hline Skin involvement & 7 & 33.33 & & & & & & & & & \\
\hline DVT & 4 & 19.05 & & & & & & & & & \\
\hline GIS involvement & 3 & 14.29 & & & & & & & & & \\
\hline Epididymitis & 1 & 4.76 & & & & & & & & & \\
\hline \multicolumn{12}{|l|}{ Localizations of CVT } \\
\hline Transverse sinus thrombosis & 14 & 66.66 & & & & 22 & 84.6 & & & & NS \\
\hline Superior sagittal sinus thrombosis & 4 & 19.05 & & & & 3 & 11.5 & & & & NS \\
\hline Sigmoid sinus thrombosis & 5 & 23.80 & & & & 5 & 19.2 & & & & NS \\
\hline Inferior sagittal sinus thrombosis & 1 & 4.76 & & & & 0 & 0 & & & & NS \\
\hline Trolard vein thrombosis & 0 & 0 & & & & 1 & 3.8 & & & & NS \\
\hline \multicolumn{12}{|l|}{ Preventive treatment } \\
\hline Colchium & 15 & 71.43 & & & & - & - & & & & \\
\hline Prednisolone & 3 & 14.29 & & & & 2 & 7.7 & & & & \\
\hline Azothioprine & 12 & 57.14 & & & & - & - & & & & \\
\hline Warfarine & 1 & 4.76 & & & & 21 & 80.7 & & & & \\
\hline Enoxaparin & - & - & & & & 1 & 3.8 & & & & \\
\hline Acetylsalicylic acid & - & - & & & & 3 & 11.5 & & & & \\
\hline Phlebotomy & - & - & & & & 2 & 7.7 & & & & \\
\hline Acetazolamide & 1 & 4.76 & & & & 1 & 3.8 & & & & \\
\hline Follow up mRS & & & & 0 & $0-1$ & & & & 0 & $0-1$ & NS \\
\hline
\end{tabular}

inferior sagittal sinus $(n=1)$, and only sigmoid sinus $(n=3)$. In group 2 , localizations of CVT were transverse sinus $(\mathrm{n}=17)$, transverse sinus and sigmoid sinus $(\mathrm{n}=3)$, superior sagittal sinus and transverse sinus $(\mathrm{n}=1)$, superior sagittal sinus and transverse sinus and sigmoid sinus $(n=1)$, sigmoid sinus $(n=1)$, sinus rectus $(n=1)$, Trolard's vein $(n=1)$, and superior sagittal sinus $(n=1)$. There was no significant difference between the groups regarding localizations of CVT (Table 1).

To treat acute CVT, group 1 was administered intravenous high dose prednisolone, while group 2 was administered anticoagulant. In group 1 , most common preventive treatments included colchium, azathioprine and prednisolone; only one patient was treated with warfarin and one patient with acetazolamide. In group 2 , most common preventive treatment was warfarin; one patient with systemic lupus erythematosus and another with Sjögren's syndrome were treated with prednisolone; one patient was treated with acetazolamide; and phlebotomy was performed in two patients with polycythemia vera. Medications used in both groups are shown in the Table 1. Median follow-up mRS score was 0 (range 0 to 1 ) in both groups. Patients' symptoms and abnormal findings improved in both groups. 


\section{DISCUSSION}

Behçet's disease may cause CVT. Akman-Demir et al. $^{2}$ reported that $10 \%$ of 200 patients with NBD had CVT. Siva et al. ${ }^{10}$ reported that $12.2 \%$ of NBD patients had CVT and the diagnosis of CVT was associated with favorable outcome. According to Yücesan et al., ${ }^{11}$ two out of 39 patients with NBD had CVT, While Gökçay et al. ${ }^{12}$ identified that 15 out of 54 patients with NBD had CVT.

Akman-Demir et al. ${ }^{2}$ reported that headache (96\%), papilledema (89\%), and sixth nerve palsy (57\%) were observed in CVT patients with BD. ${ }^{2}$ Yesilot et al. ${ }^{13}$ compared 36 CVT patients with $\mathrm{BD}$ and 32 patients with CVT related to other etiological causes and found that isolated intracranial hypertension was the most common symptom in CVT patients with $\mathrm{BD}$. All of the patients had good outcome and six of them had clinical recurrences. Wechsler et al. ${ }^{14}$ also suggested that the most frequent manifestation of CVT was intracranial hypertension. Houman et al. $^{15}$ reported 24 CVT patients with BD and suggested that headache was the most common neurologic symptom in 15 CVT patients. Compatible with previous reports and regardless of the presence of $\mathrm{BD}$, intracranial hypertension was the most common presentation of CVT in our study. There was no significant difference between the CVT patients with or without $\mathrm{BD}$ regarding age, sex, neurological symptoms or findings. Therefore, according to our study results, the demographic and clinical findings of CVT are similar independently of the cause of CVT.

In the literature, the most and the second most common localizations of CVT have been reported as superior sagittal and transverse sinus in CVT patients with BD. . $^{3,-13,16-32}$ Moreover, a single sinus occlusion has been reported as a more common finding than multiple occlusions in CVT patients with or without BD. ${ }^{32,33}$ Similar with the previous studies, we detected that single sinus occlusion was more frequent then multiple occlusions in CVT patients with or without BD in our study. Although there was no difference in the localization of occluded sinus between CVT patients with or without BD in our study, we found that transverse sinus was the most common and sagittal sinus was the second most common affected sinus in CVT patients with BD contrary with previous reports. Further studies including more CVT patients with BD are needed to evaluate this result.

Most CVT patients with BD has been treated with prednisolone in acute CVT attacks. ${ }^{[2,9,11-17,20,30,34-40]}$ Moreover, warfarin and acetyl salicylic acid have been given to some CVT patients with BD. ${ }^{10-12,17,26,34}$ Wechsler et al. ${ }^{14}$ reported that treatment of CVT during acute phase consisted of combined heparin and steroids in 19 patients, steroids alone in three, and heparin alone in three others. Neurologic symptoms improved rapidly in all. Nineteen patients were treated by long-term anticoagulation, and two patients were treated with aspirin. The outcome was favorable in treated patients after more than three years of follow-up period. ${ }^{14}$ Saadoun et al. ${ }^{16}$ evaluated 64 patients (7.8\%) with CVT out of 820 patients with BD. The treatment of acute CVT consisted of anticoagulation in 62 (96\%) and steroids in 54 (84.4\%) patients. The short time outcome was favorable, but sequels of CVT were noted in 23 patients (35.9\%). These sequels were blindness $(n=6)$, persistent headache $(n=6)$, decreased visual acuity $(n=4)$, altered cognition $(n=3)$, hemiparesis $(n=2)$, and tinnitus $(n=2) .{ }^{16}$ Yesilot et al. ${ }^{13}$ reported that anticoagulants were not used for treatment of CVT in their BD patients except for one case with venous infarction; they treated the patients with immunosuppressant drugs similar to other NBD patients.

All of our patients were treated with intravenous high dose prednisolone for acute CVT in group 1; one patient was also given warfarin because of the presence of homozygous Factor $\mathrm{V}$ Leiden mutation and another case was also given acetazolamide because of high intracranial pressure. All patients' symptoms improved; thus, we thought that response to high dose steroid treatment in acute CVT is good, and anticoagulation may not be necessary in the treatment of CVT patients with BD unless the presence of thrombophilia. It is known that anticoagulant treatment may be harmful in cases with systemic aneurisms in BD since it may result in bleeding; therefore, avoidance of anticoagulant treatment is important in these patients. ${ }^{35}$

Colchium, prednisolone, azathioprine, cyclosporine, and cyclophosphamide have 
been administered to prevent the recurrence of CVT in BD. ${ }^{2,9,15,17,26-28,30,36-42}$ Acetazolamide and lumboperitoneal shunts have been installed to reduce intracranial hypertension in some CVT patients with $\mathrm{BD} .^{20,25}$ We administered colchium, azathioprine, and/or prednisolone to our patients to prevent recurrence and we have not observed any recurrence during follow-up in CVT patients with BD. Most of our CVT patients without BD were treated with anticoagulants. Follow-up mRS score was similar in CVT patients with or without $\mathrm{BD}$ and both groups displayed favorable results at follow-up. Therefore, we may suggest that treatment response is good in CVT patients independently of the causes of CVT.

A limitation of our study is that this is a retrospective study with a small sample size.

In conclusion, both clinical and radiological findings were similar in CVT patients with or without $\mathrm{BD}$ in our study. Although treatment medications were different between groups in acute CVT period, both group's treatment responses were similarly good. Prednisolone seemed useful in treatment of acute CVT attacks in CVT patients with BD. On the other hand, there is a risk of systemic aneurism and bleeding in case of anticoagulant treatment. In our study, symptoms of all patients improved with steroid treatment and steroid treatment appeared to be useful in treatment of acute CVT attacks in CVT patients with $\mathrm{BD}$. However, this issue should be investigated in further studies. In line with previous reports and based on the results of our study, we suggest that treatment with prednisolone may be sufficient and anticoagulation therapy may not be necessary for the treatment of acute CVT attacks in $\mathrm{BD}$.

\section{Declaration of conflicting interests}

The authors declared no conflicts of interest with respect to the authorship and/or publication of this article.

\section{Funding}

The authors received no financial support for the research and/or authorship of this article.

\section{REFERENCES}

1. Behçet $H$. Über rezidivierende, aphthöse, durch ein Virus verursachte Geschwüre am Mund, am Auge und an den Genitalien. Derm Wschr 1937;105:1152-7.

2. Akman-Demir G, Serdaroglu P, Tasçi B. Clinical patterns of neurological involvement in Behçet's disease: evaluation of 200 patients. The NeuroBehçet Study Group. Brain 1999;122:2171-82.

3. Al-Araji A, Kidd DP. Neuro-Behçet's disease: epidemiology, clinical characteristics, and management. Lancet Neurol 2009;8:192-204.

4. International team for the revision of the international criteria for Behcet's disease. Evaluation of the international criteria for Behcet's disease (ICBD) Clinical and Experimental Rheumatology 2006;24(Suppl. 42):S13.

5. Dutra LA, Gonçalves CR, Braga-Neto P, Pedroso JL, Gabbai AA, Barsottini OG, et al. Atypical manifestations in Brazilian patients with neuroBehçet's disease. J Neurol 2012;259:1159-65.

6. Siva A, Altintas A, Saip S. Behçet's syndrome and the nervous system. Curr Opin Neurol 2004;17:347-57.

7. Bousser MG, Bletry O, Launay M, Portier E, Guillard A, Castaigne P. Cerebral venous thrombosis in Behçet's disease (author's transl). Rev Neurol (Paris) 1980;136:753-62. [Abstract]

8. Borer H, Rüttimann S, Kätterer C. Cerebral sinus vein thrombosis in Behçet's disease. Schweiz Med Wochenschr 1991;121:788-92. [Abstract]

9. Lizarazo-Barrera JC, Jacobelli S, Mellado P, González $\mathrm{S}$, Massardo L. Extensive cerebral vein thrombosis as first manifestation of Behçet's disease. Report of one case. Rev Med Chil 2010;138:746-51. [Abstract]

10. Siva A, Kantarci OH, Saip S, Altintas A, Hamuryudan $\mathrm{V}$, Islak $\mathrm{C}$, et al. Behçet's disease: diagnostic and prognostic aspects of neurological involvement. $\mathrm{J}$ Neurol 2001;248:95-103.

11. Yücesan C, Isikay CT, Ozay E, Aydin N, Mutluer N. The clinical involvement patterns of neuro-Behçet's disease. Eur J Neurol 2001;8:92.

12. Gökçay F, Celebisoy N, Gökçay A, Aksu K, Keser G. Neurological symptoms and signs in Behçet disease: a Western Turkey experience. Neurologist 2011;17:147-50.

13. Yesilot N, Bahar S, Yilmazer S, Mutlu M, Kurtuncu M, Tuncay R, et al. Cerebral venous thrombosis in Behçet's disease compared to those associated with other etiologies. J Neurol 2009;256:1134-42.

14. Wechsler B, Vidailhet M, Piette JC, Bousser MG, Dell Isola $\mathrm{B}$, Blétry $\mathrm{O}$, et al. Cerebral venous thrombosis in Behçet's disease: clinical study and long-term followup of 25 cases. Neurology 1992;42:614-8.

15. Houman MH, Bellakhal S, Ben Salem T, Hamzaoui A, Braham A, Lamloum M, et al. Characteristics of neurological manifestations of Behçet's disease: a retrospective monocentric study in Tunisia. Clin Neurol Neurosurg 2013;115:2015-8.

16. Saadoun D, Wechsler B, Resche-Rigon M, Trad S, Le Thi Huong $\mathrm{D}$, Sbai $\mathrm{A}$, et al. Cerebral venous thrombosis in Behçet's disease. Arthritis Rheum 
2009;61:518-26.

17. Farah S, Al-Shubaili A, Montaser A, Hussein JM, Malaviya AN, Mukhtar M, et al. Behçet's syndrome: a report of 41 patients with emphasis on neurological manifestations. J Neurol Neurosurg Psychiatry 1998;64:382-4.

18. Bouchez B, Arnott G, Caron JC, Guerouaou D, Clarisse G, Blondel $\mathrm{M}$, et al. Cerebral venous thrombosis with involvement of the cavernous sinus. Initial manifestation of Behçet's disease?. Rev Otoneuroophtalmol 1984;56:447-53. [Abstract]

19. Harper CM Jr, O'Neill BP, O'Duffy JD, Forbes GS. Intracranial hypertension in Behçet's disease: demonstration of sinus occlusion with use of digital subtraction angiography. Mayo Clin Proc 1985;60:419-22.

20. Wechsler B, Bousser MG, Huong Du LT, Bletry O, Le Hoang P, Godeau P. Cerebral venous sinus thrombosis in Behçet's disease. Mayo Clin Proc 1985;60:891-2.

21. el-Ramahi KM, al-Kawi MZ. Papilloedema in Behçet's disease: value of MRI in diagnosis of dural sinus thrombosis. J Neurol Neurosurg Psychiatry 1991;54:826-9.

22. Huss GP, Mattle H, Wessel K, Mumenthaler M. NeuroBehçet's syndrome: encephalitis and cerebral venous thrombosis--clinical aspects and neuroradiology of 5 cases. Nervenarzt 1992;63:352-8. [Abstract]

23. Türk $U$, Aribaş E, Aydin N. Cerebral venous thrombosis in Behçet's disease. Tokai J Exp Clin Med 1994;19:19-22.

24. Swerdlow RH, Hanna GR. Behcet's disease: presentation with sagittal sinus thrombosis diagnosed noninvasively. Headache 1996;36:115-8.

25. el Bahri Ben Mrad F, Fredj M, Skandrani L, Kaddour C, Gouider R, Mrabet A. Cerebral venous thrombosis and Behcet's disease. Tunis Med 2002;80:87-9. [Abstract]

26. Chaloupka K, Baglivo E, Hofer M, Chizzolini C, Delavelle J, Rossillion B, et al. Cerebral sinus thrombosis in Behçet disease: case report and review of the literature. Klin Monbl Augenheilkd 2003;220:186-8. [Abstract]

27. Limotai $C$, Phanthumchinda K. Cerebral venous sinus thrombosis in Behcet's disease: a case report. J Med Assoc Thai 2004;87:845-9.

28. Rahil AI, Errayes M, Salem KM. Cerebral venous thrombosis as the initial presentation of Behcet's disease. Chang Gung Med J 2009;32:220-3.

29. Schytz HW, Wegener M, Lassen LL. Cerebral venous thrombosis in Behçet's disease. Ugeskr Laeger 2012;174:1385-6. [Abstract]

30. Tascilar NF, Akman-Demir G, Demiryurek BE,
Tokgoz O, Akgun N, Ozen Barut B. An unusual case of neuro-Behçet's disease presenting with co-occurence of cerebral venous sinus thrombosis with basilar artery occlusion. Neurol Sci 2013;34:785-8.

31. Marih L, Sodqi M, Marhoum El Filali K, Chakib A. Behçet's disease revealed by deep vein thrombosis in an HIV-1-infected patient. J Mal Vasc 2012;37:320-2. [Abstract]

32. Aydin AE, Gunduz O, Sari I, Saatci AO, Yilmaz E, Akkoc N. Papilledema caused by cerebral venous sinus thrombosis in a patient with Behçet disease. $\mathrm{J}$ Clin Rheumatol 2013;19:52.

33. Ferro JM, Canhão P, Stam J, Bousser MG, Barinagarrementeria F. Prognosis of cerebral vein and dural sinus thrombosis: results of the International Study on Cerebral Vein and Dural Sinus Thrombosis (ISCVT). Stroke 2004;35:664-70.

34. Humberclaude V, Vallée L, Sukno S, Vamecq J, Dhellemmes S, Pruvo JP, et al. Cerebral venous thrombosis disclosing Behçet disease. Arch Fr Pediatr 1993;50:603-5. [Abstract]

35. Kalra S, Silman A, Akman-Demir G, Bohlega S, Borhani-Haghighi A, Constantinescu CS, et al. Diagnosis and management of Neuro-Behçet's disease: international consensus recommendations. $\mathrm{J}$ Neurol 2014;261:1662-76.

36. Al-Fahad SA, Al-Araji AH. Neuro-Behcet's disease in Iraq: a study of 40 patients. J Neurol Sci 1999;170:105-11.

37. Lannuzel A, Lamaury I, Charpentier D, CaparrosLefebvre D. Neurological manifestations of Behçet's disease in a Caribbean population: clinical and imaging findings. J Neurol 2002;249:410-8.

38. Joseph FG, Scolding NJ. Neuro-Behçet's disease in Caucasians: a study of 22 patients. Eur J Neurol 2007;14:174-80.

39. Riera-Mestre A, Martínez-YelamosS, Martínez-Yelamos A, Ferrer I, Pujol R, Vidaller A. Clinicopathologic features and outcomes of neuro-Behçet disease in Spain: a study of 20 patients. Eur J Intern Med 2010;21:536-41.

40. Hirohata S, Kikuchi H, Sawada T, Nagafuchi H, Kuwana $\mathrm{M}$, Takeno $\mathrm{M}$, et al. Clinical characteristics of neuroBehcet's disease in Japan: a multicenter retrospective analysis. Mod Rheumatol 2012;22:405-13.

41. Peño IC, De las Heras Revilla V, Carbonell BP, Di Capua Sacoto D, Ferrer ME, García-Cobos R, et al. Neurobehçet disease: clinical and demographic characteristics. Eur J Neurol 2012;19:1224-7.

42. Yoon DL, Kim YJ, Koo BS, Kim YG, Lee CK, Yoo B. Neuro-behçet's disease in South Korea: clinical characteristics and treatment response. Int $\mathrm{J}$ Rheum Dis 2014;17:453-8. 